\title{
Aspek Budaya Prancis dalam Metropop Autumn In Paris Karya Ilana Tan
}

\author{
Tania Intan ${ }^{1}$ \\ ${ }^{1}$ Departemen Susastra dan Kajian Budaya, Fakultas Ilmu Budaya, Universitas Padjadjaran \\ J1. Raya Bandung-Sumedang Km. 21,7 Jatinangor, Sumedang 45363 \\ Penulis untuk Korespondensi/ E-mail: tania.intan@unpad.ac.id
}

\begin{abstract}
This study aims to reveal the aspects of French culture in Ilana Tan's metropolitan novel Autumn in Paris and to analyze its significance for the narrative developed by the author. The research method used is descriptive analysis, with the sociology of literature approach and structural studies. Data in the form of words, phrases, and sentences relating to aspects of French culture in the object of research were collected using the observation and note technique. The data are then classified and interpreted with relevant theories. The results of this study indicate that the aspects of French culture presented include the naming of characters, physical depictions and characters of French people, the use of place settings in France, descriptions of French culinary delights, and French people's daily activities. The depiction of this aspect of French culture is not specific and the elements mentioned are still superficial knowledge for the reader. The use of French terms and words is very minimalistic. There is an introduction of multicultural phenomena but they are not developed further. Overall, it can be stated that the aspects of French culture that Ilana Tan presents in Autumn in Paris are stereotypical and purely decorative.
\end{abstract}

Abstrak - Penelitian ini bertujuan untuk mengungkap aspek-aspek budaya Prancis dalam novel metropop Autumn in Paris karya Ilana Tan serta mengkaji signifikansinya terhadap narasi yang dibangun oleh pengarang. Metode penelitian yang digunakan adalah deskriptif analisis, dengan pendekatan sosiologi sastra dan kajian struktural. Data berupa kata, frasa, dan kalimat yang berkaitan dengan aspek budaya Prancis dalam objek penelitian dikumpulkan dengan teknik simak dan catat. Data kemudian diklasifikasi dan diinterpretasi dengan teori-teori yang relevan. Hasil penelitian ini menunjukkan bahwa aspek-aspek budaya Prancis yang ditampilkan meliputi penamaan tokoh, penggambaran fisik dan karakter orang Prancis, penggunaan latar tempat di Prancis, deskripsi kuliner Prancis, dan aktivitas keseharian orang Prancis. Penggambaran aspek budaya Prancis tersebut tidak bersifat spesifik dan elemen-elemen yang disebutkan masih merupakan pengetahuan superfisial bagi pembaca. Penggunaan istilah dan kata-kata berbahasa Prancis pun sangat minimalis. Ada introduksi fenomena multikultural namun tidak dikembangkan lebih jauh. Secara keseluruhan, dapat dinyatakan bahwa aspek budaya Prancis yang ditampilkan Ilana Tan pada novel Autumn in Paris bersifat stereotipikal dan dekoratif.

Keywords - French culture, Ilana Tan, Metropop, Stereotype

\section{PENDAHULUAN}

$\mathrm{I}$ lana Tan adalah seorang novelis Indonesia yang dikenal melalui novel-novelnya yang bergenre metropop. Sosoknya sendiri misterius. Ia tidak pernah melampirkan foto pada bukunya atau mengadakan meet and greet bagi para penggemarnya. Namun, karya-karyanya selalu sukses di pasaran hingga dicetak ulang berkali-kali dan mencapai angka penjualan rata-rata 110.000 eksemplar masing-masingnya [1]. Karyanya paling terkenal, Tetralogi Empat Musim, merupakan empat novel metropop yang menggunakan latar luar negeri yang berbeda-beda, yaitu: Jepang (Winter in Tokyo), Prancis (Autumn in Paris), Korea Selatan (Summer In Seoul), dan Inggris (Spring in London).

Dari penelitian Intan dkk. [2], diketahui bahwa Sandy merupakan protagonis novel Summer in Seoul, Tara pada Autumn in Paris, Keiko pada 
Winter in Tokyo, dan Naomi pada Spring in London. Meskipun masing-masing bukan merupakan kelanjutan dari novel yang lain, ada relasi di antara tokoh-tokoh tersebut. Sandy merupakan saudara sepupu Tara, sedangkan Keiko adalah saudara kembar Naomi. Di antara para tokoh laki-laki pun ada hubungan pertemanan, seperti Danny Jo (pacar Naomi) dengan Jung Tae-Wo (pacar Sandy). Unsur yang juga mempersatukan keempat novel adalah keterkaitan para tokoh perempuan dengan Indonesia, yang menunjukkan bahwa mereka berdarah Asia. Ibu Sandy berasal dari Indonesia dan menikah dengan laki-laki Korea, sedangkan ibu Tara yang merupakan warga negara Indonesia pernah menikah dengan ayah Tara, seorang laki-laki Prancis. Demikian pula dengan Keiko dan Naomi yang memiliki ibu yang berasal dan masih tinggal di Indonesia, sementara mereka tinggal di Jepang dan London.

Sesuai dengan judul novel, masing-masing dikisahkan dengan latar tempat dan budaya berbedabeda, yaitu Seoul, Paris, Tokyo, dan London. Selain itu, sebagaimana namanya, musim menjadi penanda waktu untuk latar dari tetralogi ini, yaitu musim dingin, musim semi, musim panas, dan musim gugur. Fenomena penggunaan latar luar negeri dalam karya fiksi ini, sebagaimana disebutkan oleh Nurhadi [3], menggambarkan ruang gerak penulis Indonesia sebagai bagian dari warga dunia dan bentuk multikulturalisme budaya luar terhadap budaya Indonesia.

Penelitian ini selanjutnya difokuskan pada kajian novel Autumn in Paris yang terbit pertama kali pada tahun 2007. Teks yang digunakan untuk telaah ini adalah cetakan ke tiga puluh dua yang terbit pada tahun 2018 [4]. Latar belakang pemilihan novel tersebut didasari oleh ketertarikan peneliti pada novel - novel kontemporer Indonesia yang menggunakan latar luar negeri terutama Prancis, serta kesesuaian bidang ilmu yang ditekuni peneliti, yaitu bahasa, sastra, dan budaya Prancis.

Novel Autumn in Paris berkisah tentang Tara Dupont, gadis blasteran Indonesia-Prancis berumur 24 tahun yang bekerja di sebuah stasiun radio di Paris. Sebelum tinggal bersama ayahnya, Tara tinggal bersama ibunya di Indonesia. Fisiknya pun lebih menyerupai orang Asia daripada Prancis. Konflik dalam novel tersebut terjadi sejak Tara mengenal dan jatuh cinta pada sosok Tatsuya, seorang laki-laki Jepang.
Selain dalam Autumn in Paris, Paris juga digunakan sebagai latar sejumlah karya fiksi lainnya. Novelnovel yang juga menggunakan latar kota Paris di antaranya adalah Paris (Prisca Primasari), Cinderella in Paris (Sari Musdar), Paris 7 Novembre (Frasio Damario), Love in Paris (Silvarani), Galette (Fenny Wong), dan From Paris to Eternity (Clio Freya). Realita ini menunjukkan bahwa Paris dianggap memiliki pesona dan potensi tersendiri yang digunakan penulis fiksi untuk mendukung keutuhan cerita.

Pemilihan latar pada penciptaan karya sastra merupakan hal yang penting karena latar adalah salah satu unsur struktural yang membangun teks, yang bila digarap dengan baik dapat berpengaruh terhadap imajinasi pembaca [5]. Sebaliknya, bila latar digambarkan dengan lemah, akan timbul ketimpangan yang berdampak pada ketidakyakinan pembaca terhadap 'kebenaran' yang dikonstruksi di dalam teks. Hal ini terjadi, karena latar akan menjadi dekor dari semua peristiwa yang terjadi di dalam karya. Latar tidak hanya menyangkut tempat dan waktu, melainkan juga nilai kehidupan manusia seperti adat istiadat, norma, dan tingkah laku. Latar tidak hanya terbatas pada pengertian geografis melainkan juga antropologis [6].

Pada hakikatnya, sebuah karya sastra, menurut Nurgiyantoro [7], tidak pernah lepas dari situasi kekosongan budaya, karena sastra mencerminkan pola kehidupan budaya yang menjadi latarnya. Dengan demikian, membaca dan mempelajari karya sastra berarti, secara langsung atau tidak langsung, berarti mengenal dan memahami kehidupan sosial budaya masyarakat yang bersangkutan. Definisi budaya di sini mencakup semua aspek kehidupan, seperti semua karya yang diciptakan, cara bertingkah laku, bergaul, berpikir, merasa, bersikap, cara memandang suatu permasalahan, maupun halhal lain yang melekat dalam kebiasaan hidup suatu bangsa [7].

Dengan mengutip Zaimar dan Esten, Suhardi [8] menyampaikan bahwa hubungan karya sastra dengan realitas sosial masyarakat tidak dapat dipungkiri keberadaannya, karena sebuah karya bersumber dari kenyataan yang hidup dalam masyarakat. Namun, yang terdapat dalam karya sastra bukan hanya realitas objektif saja, melainkan juga "terpancar pemikiran, kehidupan, dan tradisi yang hidup dalam suatu masyarakat. Oleh karenanya, berbicara tentang kesusastraan berarti juga membicarakan kebudayaan.” 
Dalam penelusuran peneliti, novel Autumn in Paris telah dikaji oleh Sitompul dkk. [9], yang menelaah jenis-jenis cinta yang diungkapkan oleh tokoh utama Tara Dupont. Penelitian tersebut menggunakan teori Segitiga Cinta dari Robert Sternberg yang menyatakan bahwa cinta memiliki tiga komponen yaitu keintiman, hasrat, dan komitmen. Selain relasi romantis, dalam novel tersebut terungkap adanya relasi pertemanan.

Sebagai satu kesatuan, Tetralogi Empat Musim telah dikaji oleh Baitaningrum [10] dengan analisis wacana kritis Sara Mills, sedangkan Alverina dkk. [11] menelaahnya secara struktural dan menemukan bahwa dalam keempat novel, para tokoh perempuan digambarkan berkarakter The Waif. Sejalan dengan penelitian tersebut, Intan dkk. [2] menyatakan bahwa perempuan dalam tetralogi tersebut ditampilkan sebagai subjek berkarakter TWITS (Teenage Women in their thirties 'remaja perempuan di usia 30-an', yaitu lajang, mandiri, bekerja pada ruang publik, berusia antara 24-30 tahun, cantik dan menarik, tinggal di daerah kota, bergaya hidup metropolis, heteroseksual, dan memiliki kelemahan. Hasil penelitian menunjukkan bahwa dengan postur dan kemandirian tersebut, perempuan secara sosial masih dicitrakan sebagai objek sistem patriarki yang digambarkan melalui ketergantungan pada protagonis laki-laki dalam hubungan percintaan.

Dari paparan terhadap penelitian terdahulu, baik terhadap novel Autumn in Paris maupun Tetralogi Empat Musim, dapat dilihat bahwa kajian-kajian tersebut menelaah citra perempuan di dalam tetralogi karya Ilana Tan dan belum menyentuh bidang lainnya. Oleh karena itu, terbuka celah untuk kelanjutan penelitian ini, yang akan berfokus terhadap aspek budaya Prancis. Dengan demikian, tujuan yang dirumuskan untuk penelitian ini adalah mengungkap aspek-aspek budaya Prancis dalam novel metropop Autumn in Paris serta mengkaji signifikansinya terhadap narasi yang dibangun oleh pengarang.

\section{METODE}

Penelitian ini menggunakan metode deskriptif analisis, yang dilakukan melalui deskripsi faktafakta yang kemudian dilanjutkan dengan analisis. Menurut Ratna [12], metode ini secara keseluruhan memanfaatkan cara penafsiran dalam bentuk deskripsi. Selain analisis struktural pada novel yang dikaji, pendekatan yang digunakan adalah sosiologi sastra, yang menelaah manusia/ tokoh dalam kaitannya dengan masyarakat. Analisis sosiologis tidak bertujuan untuk mereduksi hakikat rekaan ke dalam fakta. Tujuan sosiologi sastra adalah mendapatkan pemahaman terhadap karya sastra dalam kaitannya dengan masyarakat, bahwa rekaan tidak berlawanan dengan kenyataan [13].

Data berupa kata, frasa, dan kalimat yang relevan dengan permasalahan penelitian dikumpulkan dari novel Autumn in Paris dengan teknik simak dan catat. Data tersebut kemudian diklasifikasi dan diinterpretasi, selanjutnya dianalisis untuk kemudian dirumuskan sebuah simpulan.

\section{HASIL DAN PEMBAHASAN}

Bagian hasil dan pembahasan dibagi menjadi tiga bagian, yaitu synopsis novel Autumn in Paris, aspekaspek budaya Prancis, dan multikulturalisme.

\section{Synopsis Novel Autumn In Paris}

Pada suatu kesempatan, Tara diperkenalkan oleh sahabatnya, Sebastian, pada Tatsuya Fujisawa. Tara dan Tatsuya kemudian bertemu lagi pada kesempatan lain dan mereka pun menjadi dekat. Alasan kedatangan Tatsuya ke Paris bukan hanya untuk pekerjaannya, melainkan juga untuk mencari seorang laki-laki Prancis yang merupakan cinta pertama ibunya.

Pada suatu hari, di klub saat ulang tahun Elise, Tara memperkenalkan ayahnya pada semua temannya yang hadir. Ayah Tara tampak gelisah ketika mendengar pengakuan putrinya, bahwa Tatsuya adalah teman dekatnya. Namun, kebenaran tidak langsung terungkap saat itu. Beberapa hari setelahnya, Tatsuya terlihat selalu murung. Ternyata setelah melakukan tes DNA, ia mengetahui bahwa ayah Tara adalah ayah kandungnya, yang berarti ia dan gadis yang ia sukai itu bersaudara. Karena kalut dengan pikirannya, Tatsuya mengalami kecelakaan. Tara pun pergi ke rumah sakit untuk mengetahui keadaan laki-laki itu. Di sana, ia melihat ayahnya. Tanpa sengaja, dari pembicaraan ayahnya dengan dokter, Tara mengetahui bahwa Tatsuya adalah kakaknya. Setelah laki-laki itu sembuh, Tara menemuinya dan menyatakan dapat menerima kenyataan itu.

Tatsuya pun kembali ke Jepang dan berusaha melupakan perasaan cintanya pada Tara. Namun sebulan setelah perpisahan mereka, Tara mendapatkan kabar bahwa laki-laki itu mengalami 
kecelakaan dan mengalami koma. Tara dan ayahnya pun pergi ke Jepang. Saat itulah Tatsuya meninggal dunia.

\section{Aspek-aspek Budaya Prancis pada Novel Autumn in Paris}

Pembahasan ini meliputi beberapa bagian yaitu: penamaan tipikal Prancis pada para tokoh, penggambaran stereotip fisik dan karakter orang Prancis, penggunaan latar fisik riil Prancis, deskripsi kuliner khas Prancis, dan penggambaran aktivitas orang Prancis.

\section{Penamaan Tipikal Prancis pada Para Tokoh}

Orang Prancis memiliki prénom 'nama depan' dan nom de famille 'nama keluarga'. Dalam novel yang dikaji, para tokoh yang dianggap penting oleh pengarang diberi nama belakang, seperti: Tara Dupont (hal. 9), Elise Lavoie (hal. 10), Sebastien Giraudeau (hal. 14), Charles Gilou (hal. 74), JeanDaniel Lemercier (hal. 90), dan Dr. Laurent Delcour (hal. 175). Sebaliknya, para tokoh pendukung yang tidak terlalu penting tidak disebutkan nama belakangnya, seperti: Hugo, Claude, Edouard (hal. 116), Olivier (hal. 113) dan juga Juliette (hal. 113).

Dalam relasi formal, ada penyebutan Madame 'nyonya/ibu', Monsieur 'tuan/bapak', dan Mademoiselle 'nona'. Dalam novel, penyebutan tersebut muncul yang ditujukan pada: Tara sebagai Mademoiselle Dupont (hal.12) dan pada ayahnya sebagai Monsieur Dupont (hal. 16). Dalam relasi informal seperti dalam keluarga atau di antara kekasih/ pasangan suami-istri, ada penyebutan yang menunjukkan keintiman seperti ma chérie 'sayangku' (hal. 46) yang digunakan oleh ayah Tara pada putrinya.

Sapaan yang lazim digunakan dalam percakapan sehari-hari adalah bonsoir 'selamat malam' (90), bonjour 'selamat siang' (hal. 92), atau dalam situasi yang lebih santai salut 'hai'. Sapaan bonjour, Monsieur lebih netral dan aman untuk digunakan daripada dengan menyebut nama seperti bonjour, Monsieur Dupont. Dalam novel Autumn in Paris, ditemukan kesalahan mendasar pada penulisan yaitu bon soir (antara bon dan soir dipisah, seharusnya digabung). Hal ini menyiratkan bahwa pengarang tidak benar-benar menguasai tata bahasa Prancis.

\section{Penggambaran Stereotip Fisik dan Karakter Orang Prancis}

Dalam novel Autumn in Paris, sosok fisik perempuan Prancis direpresentasikan oleh Elise, sahabat Tara, yang bertubuh langsing, modis, dan awet muda.

Elise manis yang berambut pirang emas sebahu, bermata hijau, dan berhidung berbintik-bintik itu berusia 29 tahun, beberapa tahun lebih tua daripada Tara, tapi secara fisik wanita itu tidak terlihat seperti wanita Eropa seusianya. Perawakannya kurus, kecil dan dengan wajah seperti gadis remaja. (hal. 10)

Realitasnya, perempuan Prancis dikenal sangat memperhatikan penampilannya dan selalu menjaga berat badannya. Tara sendiri, sebagai tokoh utama, tidak mencerminkan ciri fisik sebagai perempuan Prancis, karena berdarah campuran Asia-Eropa. Laki-laki Prancis direpresentasikan dalam novel ini melalui ayah Tara, Tuan Dupont/ Lemercier. Meskipun tidak lagi muda, laki-laki ini merawat diri dengan baik dan berkesan awet muda.

Ayah Tara, Monsieur Dupont, adalah tipikal orang Eropa, jangkung, tampan, dengan rambut cokelat terang, hidung mancung, mata kelabu, dan kulit putih pucat [...] (hal. 16)

Sebastien merupakan gambaran dari laki-laki muda Prancis yang metroseksual, yang sangat memperhatikan penampilannya. Atensi khusus ini selain berkaitan dengan pekerjaan juga berkorelasi langsung dengan karakter stereotipik laki-laki Prancis yang 'playboy' sehingga ingin memberi kesan baik dan terpelajar pada perempuan.

Laki-laki itu terkekeh pelan dan menunduk. Rambutnya yang dipotong rapi jatuh menutupi dahinya. "Aku sedang bertanyatanya apakah kau mau menemaniku makan malam.”

Dasar laki-laki Prancis! Tara menggerutu dalam hati. (hal. 13)

Tara memutuskan hubungan dan mendecakkan lidah. Kenapa ia dikelilingi pria mata keranjang? Papa sama saja dengan Sebastien. (hal. 36)

Orang Prancis dikenal memiliki karakter chauvinistik dan sangat bangga dengan sejarah dan budaya bangsanya. Itulah sebabnya, dalam masyarakat Prancis, terdapat banyak orang yang hanya bersedia berkomunikasi dalam bahasanya dan menghindari untuk berbicara bahasa Inggris. Oleh karena itu, orang asing yang memiliki kapasitas berbahasa Prancis [dengan cukup fasih] akan mendapat apresiasi tersendiri dari orang Prancis. 
"Kau yang selalu merasa semua orang di dunia harus bisa berbahasa Prancis. Tapi masalahnya bukan itu." (hal. 20)

Orang Prancis melafalkan huruf ' $r$ ' dengan cara yang berbeda dengan orang Indonesia, karena itu nama Tara selalu terdengar aneh kalau diucapkan dalam lafal Prancis. Selama ini hanya keluarganya yang di Indonesia yang bisa mengucapkan namanya dengan tepat. (hal. 22)

Kebanggaan orang Prancis pada bahasa dan budayanya ini ternyata berpengaruh pada kemampuan berbahasa Inggris pada sebagian besar dari mereka. Level insuffisant dan médiocre 'sangat kurang' dalam menggunakan bahasa Inggris melekat erat pada orang Prancis. Hal ini dijelaskan Pruvost [14] berkaitan dengan pandangan bahwa penguasaan bahasa internasional pertama tersebut tidak dianggap sebagai sesuatu yang krusial. Mereka yang dapat berkomunikasi dengan baik dalam bahasa Inggris terbatas pada generasi muda profesional.

Pada awalnya Sebastien tidak terlalu peduli pada Tara karena menganggap gadis itu hanya orang asing yang belum bisa berbahasa Prancis, tapi ia salah. Bahasa Prancis Tara tanpa cela dan Sebastien langsung kagum, apalagi setelah tahu selain bahasa Prancis dan Indonesia, gadis itu juga menguasai bahasa Inggris. Bahasa Inggris Sebastien yang orang Prancis buruk sekali, sampai-sampai dia malu pada gadis Asia ini. (hal. 16)

Gaya pergaulan di antara orang Prancis menyerupai gaya pergaulan masyarakat Eropa, yaitu saling menempelkan pipi ketika bertemu atau berpisah. Jumlah cium pipi (2, 3, atau 4 kali) bergantung pada adat dan kebiasaan setempat [15].

"Sampai jumpa." Tara merangkul Sebastien dan menempelkan pipinya di pipi Sebastien dengan cepat, setelah itu ia melambai kepada Tatsuya dan keluar dari restoran. (hal. 25)

Dari pembacaan terhadap novel Autumn in Paris, ternyata tidak banyak ditemukan penggunaan kata, frasa, atau kalimat dalam bahasa Prancis. Kata yang cukup banyak muncul adalah Allô 'halo'. Allô adalah bentuk sapaan yang umumnya digunakan saat seseorang menelpon atau menerima telpon. Namun, ditemukan adanya inkonsistensi, sebagaimana ditunjukkan oleh sapaan Tara pada ayahnya di telepon berikut ini.
"Halo? Oh, Papa!" Tara memindahkan ponselnya dari telinga kiri ke telinga kanan. "Malam ini? Tidak bisa ... Mm, aku sudah punya janji ... (hal. 107)

Selain penggunaan sapaan 'Halo' -alih-alih allôsebagaimana diperlihatkan pada kutipan tersebut, ditemukan pula penggunaan sapaan Allô ketika tokoh Tatsuya dan Sebastien bertemu. Sebenarnya, lebih tepat jika digunakan sapaan Salut 'hai' dalam konteks tersebut.

"Allô, Teman. Dari mana saja kau seharian ini?"

Tatsuya menoleh dan mendapati Sebastien sudah berdiri di depan meja kerjanya.

"Oh, halo, Sebastien," balasnya pelan. (hal. 154)

Selain kata Allô, kata dan frasa lain dalam bahasa Prancis yang ditemukan hanya Voilà 'ini dia' (hal. 26) dan J'ai peur ..' aku takut' (hal. 248). Realita ini menunjukkan bahwa kemungkinan besar pengarang tidak [terlalu] menguasai bahasa Prancis dan tidak terlalu berusaha untuk memasukkan unsur-unsur bahasa Prancis dalam cerita, karena kemungkinan ingin lebih berfokus pada jalannya narasi yang lancar sehingga tidak menyulitkan proses pembacaan.

Dari pembahasan mengenai penampilan fisik dan karakter orang Prancis yang ditampilkan di dalam novel yang dikaji, terungkap bahwa informasi yang ditampilkan secara stereotipikal. Hal ini menunjukkan bahwa pengarang mendeskripsikan para tokoh sesuai dengan gambaran sederhana yang umum dimiliki oleh masyarakat dan tidak dijamin kebenarannya.

\section{Penggunaan Latar Fisik Prancis}

Dalam novel Autumn in Paris, selain Paris (hal. 12) juga disebutkan kota lain yaitu Nice (hal. 33) yang terletak di sebelah tenggara negara Prancis. Paris yang ditampilkan memiliki atmosfer romantis dan memiliki kuasa untuk mengubah suasana hati. Hal ini dinyatakan oleh Tatsuya yang awalnya memiliki kesan buruk tentang kota itu karena mengingatkannya pada ayah kandungnya yang tinggal di kota itu.

"Kalau boleh jujur, dulunya aku sama sekali tidak suka Paris. Aku juga benci musim gugur." $[\ldots]$ 
"Tetapi akhir-akhir ini aku merasakan sesuatu yang aneh sedang terjadi ... Paris berubah menjadi kota yang indah tepat di depanku dan musim gugur juga mulai terasa menyenangkan. Gadis itu yang membuat segalanya berubah. Dia sangat suka kota ini dan sangat suka musim gugur. (hal. 83)

Beberapa tempat penting dan ikonik di kota Paris yang ditampilkan dan menjadi latar cerita adalah Musée Rodin (hal. 52), Eiffel dan Arc de Triomphe (hal. 54), serta Ile de la Cité dan gereja Notre Dame [de Paris] (hal. 195). Tempat-tempat lain di Paris yang disebutkan dalam novel Autumn in Paris adalah Quartier Latin (hal. 15), bandara Charles de Gaulle (hal. 27), museum Louvre dan Musée d'Orsay (hal. 52), Jardin du Luxemburg, Boulevard Saint-Germain, dan rue de Grenelle (hal. 54), Sungai Seine (hal. 81), Disneyland (hal. 85), klab La Vue (hal. 112), dan Rive Droite - Rive Gauche (hal. 194).

Lalu mereka ke Ile de la Cité dan Notre Dame. Tentu saja katedral itu juga sudah ditutup untuk umum.

"Kita memilih waktu yang payah untuk berkunjung," desah Tatsuya sambil mengagumi arsitektur Gotik yang menakjubkan dari katedral yang selesai dibangun sekitar abad 12 itu (hal. 195).

Salah satu tempat di Prancis yang mendapat perhatian khusus dalam penceritaan adalah puncak Arc de Triomphe. Monumen pembebasan rakyat Prancis yang dibangun tahun 1806 ini berada dalam satu garis lurus dengan La Défense, Champs Elysées (jalan utama yang menjadi pusat perbelanjaan dan kantor-kantor pemerintahan yang penting di Prancis, dan berakhir di Royal du Palais (istana raja) [16].

"Sebastien dan aku suka sekali melihat pemandangan kota Paris dari puncak Arc de Triomphe," katanya dengan mata berbinarbinar.

"Benar-benar menakjubkan! Banyak orang lebih suka melihat kota Paris dari puncak Eiffel, tapi menurutku pemandangan dari puncak Arc de Triomphe adalah yang terbaik. Bisa membuatmu sulit bernapas. (hal. 54)

Bangunan monumental ini didatangi oleh Tara dan Tatsuya, pertama saat mereka berkencan, dan kedua saat Tara ingin menyepi untuk melupakan luka hatinya karena mengetahui kenyataan bahwa lakilaki yang disayanginya adalah saudara seayah.

\section{Deskripsi Kuliner Khas Prancis}

Gastronomi atau dunia kuliner Prancis sebenarnya merupakan kekayaan budaya yang sangat dibanggakan oleh masyarakat negara itu. Menurut Menegaux, yang dikutip Cholsy [17], budaya gastronomi dalam masyarakat Prancis merupakan praktik sosial yang mengakar dan menjadikan jamuan makan sebagai perayaan atas momenmomen penting dalam kehidupan individu atau suatu komunitas. Makan bukan hanya berarti mengisi perut tapi ada nilai tertentu di dalamnya.

Namun, di dalam novel Autumn in Paris, sangat sedikit jenis makanan dan minuman khas Prancis yang disebutkan, yaitu: café crème 'espresso dengan krim' (hal. 28), tisane 'teh herbal' (hal. 209), croissant 'roti berbentuk bulan sabit'(hal. 210). Makanan yang jelas disebutkan justru adalah sate kambing (hal. 23) yang disukai oleh Tara. Hal ini dapat diinterpretasikan bahwa tokoh tersebut memiliki kecenderungan selera lebih sebagai orang Indonesia daripada orang Prancis. Implikasi lain dari terbatasnya nama makanan/minuman khas Prancis yang disebutkan dalam novel ini berkaitan dengan pengetahuan pengarang tentang menu dalam budaya Prancis umumnya.

Selain nama makanan dan minuman, dalam novel juga ditampilkan beberapa tempat makan khas Prancis, yaitu: bistro (hal. 14), brasserie (hal. 36), café, dan restaurant, merupakan tempat-tempat makan dan minum warga Prancis yang memiliki karakteristik, penampilan, dan menu berbeda. Menurut Chevalier-Karvis [18], bistro adalah restoran kecil yang menyajikan jenis makanan spesifik, berbeda dengan restoran yang menawarkan banyak ragam hidangan. Brasserie merupakan tempat makan yang buka hingga malam hari dan biasanya menyajikan makanan cepat saji, tempatnya cukup luas dan terbuka.

\section{Penggambaran Aktivitas Orang Prancis}

Dalam novel Autumn in Paris, digambarkan bahwa orang Prancis selain menggunakan taksi, lebih memilih menggunakan alat transportasi métro 'kereta bawah tanah' (hal. 12) karena lebih cepat, mudah, praktis, dan menjangkau banyak tempat. Ada beberapa kegiatan sehari-hari yang biasa dilakukan oleh orang Prancis selepas bekerja yang disebutkan dalam novel tersebut, seperti mendengarkan siaran radio Je me souviens 'aku mengenang' (hal. 10). Orang Prancis juga gemar menonton film. Dalam novel disebutkan bahwa selain film Prancis, mereka juga menyukai film 
Hollywood yang dialihsuarakan ke dalam bahasa Prancis (hal. 194).

Perempuan Prancis yang direpresentasikan oleh Tara dan Elise disebutkan senang berbelanja. Untuk mengetahui tren terbaru fashion, make up, dan gaya hidup, perempuan membaca majalah yang salah satunya adalah Elle (hal. 219). Prancis, terutama Paris, memang dikenal sebagai salah satu kiblat mode dunia. Di jalan Champs Elysées, berderet butik-butik Chanel, Louis-Vuitton, Pierre Cardin, serta Yves Saint-Laurent dan disainer ternama lainnya.

Orang Prancis juga biasa membuat perayaanperayaan untuk hari penting seperti ulang tahun [15]. Biasanya disediakan kue dan kado pada acara tersebut sebagaimana terlihat pada perayaan ulang tahun Tatsuya yang dipersiapkan oleh Tara di sebuah restoran.

Tatsuya terpana melihat kue yang diletakkan di depannya itu, terlebih lagi ketika tiga pelayan mulai menyanyikan lagu ulang tahu untuknya. Ia sampai kehilangan kata-kata.

"Aku membelinya tadi sore," kata Tara setelah lagu berakhir. (hal. 164)

Secara umum, novel Autumn in Paris lebih banyak menarasikan relasi di antara para tokoh dan tidak memberi deskripsi yang memadai tentang perilaku dan kehidupan masyarakat Prancis. Dalam konteks ini, latar bersifat dekoratif dan tidak terlalu berpengaruh pada tokoh.

\section{Multikulturalisme dalam Novel Autumn in Paris}

Multikulturalisme merupakan cara memandang dan menyikapi perbedaan [19]. Fenomena ini hadir di dalam novel Autumn in Paris, yang mengakomodasi kontribusi berbagai budaya, di antaranya Prancis, Indonesia, Jepang, dan Korea. Seperti telah dijelaskan pada bagian awal pembahasan, tokoh Tara adalah anak dari perempuan Indonesia yang menikah dengan laki-laki Prancis. Postur tubuh dan kondisi fisiknya pun tidak menyerupai perempuan Eropa.

Tara Dupont, memiliki ciri-ciri dominan orang Asia, dengan rambut hitam yang dipotong pendek dan kulit yang putih, tapi tidak pucat. (hal. 16)

Tokoh Tatsuya pun memiliki identitas budaya tersendiri, karena ia adalah anak seorang perempuan Jepang dan laki-laki Prancis. Di kemudian hari diketahui bahwa laki-laki Prancis yang dimaksud adalah Monsieur Lemercier/ Dupont, yaitu ayah Tara.

"Sebelum bertemu dengan ayahku, ibuku pernah jatuh cinta dengan seorang pria Prancis ... Cinta pertamanya. Karena itu ibuku memintaku mencarinya." (hal. 79)

Selain Tara dan Tatsuya, ada tokoh lain yang diceritakan merupakan anak dari hubungan perkawinan campuran, yaitu Keiko, teman Tatsuya di Tokyo, yang memiliki ibu orang Indonesia dan ayah orang Jepang (hal. 60). Tara juga memiliki sepupu yang di Korea (hal. 19).

Selain berkaitan dengan kebangsaan dan latar budaya para tokohnya yang beragam, dalam novel Autumn in Paris juga ditunjukkan restoran yang menyediakan kuliner dari negara-negara berbeda, seperti bistro yang menyediakan makanan Indonesia seperti sate kambing (hal. 23) dan restoran Italia (hal. 70) yang biasa dikunjungi oleh Tara dan Sebastien.

Berbeda dengan kajian Herlina [20], agama dan kepercayaan tidak menjadi hal yang lazim dibahas di dalam pranata sosial dan budaya Prancis, karena negara ini menerapkan laïcité atau sekularisme. Oleh karenanya, di dalam novel Autumn in Paris pun tidak ditemukan indikasi apapun yang berkaitan dengan agama dan kepercayaan para tokoh.

Dari seluruh pembahasan ini, diketahui bahwa paparan pengarang mengenai aspek budaya Prancis dalam novel karya Ilana Tan ini tidak spesifik atau dapat dikatakan artifisial saja karena berada di tataran permukaan. Tidak terungkap adanya informasi yang lengkap tentang aspek budaya Prancis. Terlebih lagi ada kesalahan-kesalahan kecil di dalam penulisan atau dalam penggunaan tuturan yang dapat diinterpretasikan sebagai kelemahan pengarang. Hal-hal yang berkaitan dengan Prancis dalam novel ini juga tidak [selalu] menggambarkan realita yang sebenarnya, namun dianggap cukup mewakili gambaran tentang masyarakat dan negara tersebut.

\section{KESIMPULAN}

Dari seluruh pembahasan ini, terungkap bahwa aspek-aspek budaya Prancis yang ditampilkan dalam novel Autumn in Paris meliputi penamaan tokoh, penggambaran fisik dan karakter orang Prancis, 
penggunaan latar tempat di Prancis, deskripsi kuliner Prancis, dan aktivitas orang Prancis.

Dari kajian, diketahui bahwa seluruh penggambaran budaya Prancis dalam novel Autumn in Paris bersifat umum, tidak spesifik, dan elemen-elemen yang disebutkan telah menjadi pengetahuan standar bagi pembaca. Penggunaan istilah dan kata-kata berbahasa Prancis juga sangat sederhana dan minimalis. Secara keseluruhan dapat dinyatakan bahwa pada novel yang dikaji, budaya Prancis yang ditampilkan bersifat stereotipikal dan cenderung artifisial. Latar budaya Prancis tidak benar-benar dieksplorasi pengarang, melainkan ditampilkan secukupnya sebagai pendukung suasana romantis yang disyaratkan oleh sebuah novel bertema percintaan. Meskipun demikian, penggambaran atmosfer kota Paris pada musim gugur sebagai latar cerita yang dieksplorasi oleh Ilana Tan dapat dinilai cukup berhasil. Kesan melankolis dan sendu direpresentasikan dengan baik oleh perilaku para tokoh dan mendukung deskripsi dari musim gugur yang ingin ditampilkan pengarang tersebut.

Pada konteks lain, penelitian terhadap novel yang menggunakan latar luar negeri masih dapat dikembangkan. Pendekatan yang potensial untuk digunakan dalam kajian lanjutan ini di antaranya adalah poskolonialisme, feminisme, antropologi sastra, serta pariwisata sastra.

\section{REFERENSI}

[1] I. Mujiarso, "Ilana Tan, Penulis Mega Bestsellers yang Misterius," DetikHOT, 25 Juni 2015. Accessed on: 26 Januari 2019Available: https://hot.detik.com/art/2952148/ilana-tanpenulis-mega-bestseller-yang-misterius

[2] T. Intan, Handayani, V. T., Sundasari, W., "Citra Perempuan dalam Novel Metropop Tetralogi Empat Musim karya Ilana Tan," Nusa, vol. 14, no. 4, pp. 583-598, 2019.

[3] Nurhadi, "Latar Luar Negeri Karya-karya Fiksi Indonesia," pp. 1-10, t.t.

[4] I. Tan, Autumn in Paris. Jakarta: Gramedia Pustaka Utama, 2018.

[5] Sakila, "Kajian Latar Fisik dan Latar Sosial yang Tercermin dalam Novel Pertemuan Dua Hati Karya N.H. Dini," Totobuang, vol. 6, no. 1, pp. 69-80, 2018.

[6] J. Sumardjo, Saini K.M Apresiasi kesusastraan. Jakarta: Gramedia Pustaka Utama, 1991.
[7] B. Nurgiyantoro, "Sastra sebagai Pemahaman Antarbudaya," Cakrawala Pendidikan, vol. 14, no. 3, pp. 1-16, 1995.

[8] Suhardi, "Nilai Budaya Minangkabau dalam Cerpen Cimuntu Lansie karya Wisran Hadi," Jurnal Bahasa Lingua Scientia, vol. 10, no. 1, pp. 17-31, 2018.

[9] R. N. M. Sitompul, M.; Purwarno, "Love in Ilana Tan's Novel Autumn in Paris," Journal of Language, vol. 1, no. 2, pp. 128-136, 2019.

[10] U. Baitaningrum, "Wacana Citra Tokoh Utama Perempuan pada Sastra Populer (Analisis Wacana Kritis Model Sara Mills pada Novel tetralogi 4 Musim Karya Ilana Tan)," Skripsi, Program Studi Ilmu Komunikasi, Universitas Kristen Satya Wacana, Salatiga, 2017.

[11] S. Alverina, Veni, Tjong, Cendrawaty, "Ciri Khas Novel Khas Ilana Tan," Skripsi, Faculty of Language and Culture, School of Chinese Literature, BINUS University, 2013.

[12] I. N. K. Ratna, Teori, Metode, dan Teknik Penelitian Sastra. Yogyakarta: Pustaka Pelajar., 2015.

[13] N. K. Ratna, Paradigma Sosiologi Sastra (Cetakan ke-4). Yogyakarta: Pustaka Pelajar, 2013.

[14] J.-A. Pruvost, "Niveau de maîtrise de l'anglais en France en 2018," Available: https://www.languagebooster.fr/niveaumaitrise-anglais-france-2018/

[15] O. Grand-Clement, Savoir-vivre avec les Français. Paris: Hachette Livre FLE, 1996.

[16] I. Santoso, "Di antara Masa Lalu-an dan Kekinian Kota Bersejarah," Mintakat Jurnal Arsitektur, vol. 2, no. 1, pp. 39-44, 2003.

[17] H. Cholsy, "Kata Serapan Bahasa Perancis sebagai Sebuah Distingsi dalam Ranah Kuliner dan Mode di Indonesia," in International Seminar Prasasti III: Current Research in Linguistics, 2012.

[18] C. Chevalier-Karfis, "Un Bistro, une Brasserie, un Restaurant? What's the Difference? ," Available:

https://www.frenchtoday.com/blog/frenchfood-wine/difference-bistro-brasserie/

[19] J. Tjahjani, "Multikulturalisme di Prancis: Masalah Asimilasi dan Integrasi. ," Available: https://staff.ui.ac.id/system/files/users/joesana. tjahjani/publication/pptbujoesana.pdf.

[20] S. Herlina, "Suatu Telaah Budaya: Agama dalam Kehidupan Orang Jepang," Jurnal AlAzhar Indonesia Seri Humaniora, vol. 1, no. 2, pp. 113-118, 2011. 